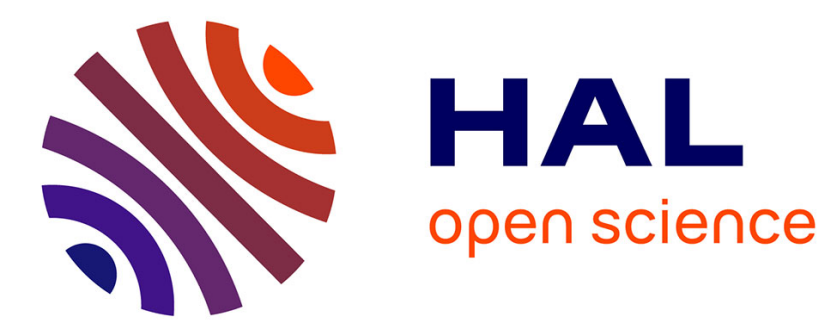

\title{
Quinone- and nitroreductase reactions of [i] Thermotoga maritima[/i] thioredoxin reductase
}

Benjaminas Valiauga, Nicolas Rouhier, Jean-Pierre Jacquot

\section{To cite this version:}

Benjaminas Valiauga, Nicolas Rouhier, Jean-Pierre Jacquot. Quinone- and nitroreductase reactions of [i]Thermotoga maritima[/i] thioredoxin reductase. Acta Biochimica Polonica, 2015, 62 (2), pp.303-309. 10.18388/abp.2015_1003. hal-01269392

\section{HAL Id: hal-01269392 \\ https://hal.science/hal-01269392}

Submitted on 27 May 2020

HAL is a multi-disciplinary open access archive for the deposit and dissemination of scientific research documents, whether they are published or not. The documents may come from teaching and research institutions in France or abroad, or from public or private research centers.
L'archive ouverte pluridisciplinaire HAL, est destinée au dépôt et à la diffusion de documents scientifiques de niveau recherche, publiés ou non, émanant des établissements d'enseignement et de recherche français ou étrangers, des laboratoires publics ou privés. 


\title{
Quinone- and nitroreductase reactions of Thermotoga maritima thioredoxin reductase
}

\author{
Benjaminas Valiauga', Nicolas Rouhier ${ }^{2,3}$, Jean-Pierre Jacquot ${ }^{2,3}$ and Narimantas Čènas ${ }^{1 凶}$ \\ IInstitute of Biochemistry of Vilnius University, LT-08662 Vilnius, Lithuania; 2Universite de Lorraine, Interactions Arbres-Microorganismes, \\ UMR1136, F-54500 Vandoeuvre-les-Nancy, France; ${ }^{3}$ INRA, Interactions Arbres-Microorganismes, UMR1136, F-54280 Champenoux, France
}

\begin{abstract}
The Thermotoga maritima NADH:thioredoxin reductase (TmTR) contains FAD and a catalytic disulfide in the active center, and uses a relatively poorly studied physiological oxidant Grx-1-type glutaredoxin. In order to further assess the redox properties of TmTR, we used series of quinoidal and nitroaromatic oxidants with a wide range of single-electron reduction potentials $\left(E^{1}{ }_{7}\right.$ $-0.49-0.09 \mathrm{~V})$. We found that TmTR catalyzed the mixed single- and two-electron reduction of quinones and nitroaromatic compounds, which was much faster than the reduction of Grx-1. The reactivity of both groups of oxidants increased with an increase in their $\mathrm{E}^{1}$, thus pointing to the absence of their structural specificity. The maximal rates of quinone reduction in the steady-state reactions were lower than the maximal rates of reduction of FAD by NADH, obtained in presteady-state experiments. The mixed-type reaction inhibition by NAD+ was consistent with its competition for a NADH binding site in the oxidized enzyme form, and also with the reoxidation of the reduced enzyme form. The inhibition data yielded a value of the standard potential for TmTR of $-0.31 \pm 0.03 \mathrm{~V}$ at $\mathrm{pH} 7.0$, which may correspond to the FAD/FADH ${ }_{2}$ redox couple. Overall, the mechanism of quinone- and nitroreductase reactions of $T$. maritima TR was similar to the previously described mechanism of Arabidopsis thaliana TR, and points to their prooxidant and possibly cytotoxic role.
\end{abstract}

Key words: thioredoxin reductase, quinones, nitroaromatic compounds, oxidative stress, Thermotoga

Received: 06 March, 2015; revised: 08 April, 2015; accepted: 28 April, 2015; available on-line: 22 June, 2015

\section{INTRODUCTION}

NAD(P)H:thioredoxin reductase (TR) and thioredoxin (TRx) systems are ubiquitous in both prokaryotes and eukaryotes, where they mainly perform antioxidant functions (Williams, 1990). TRs are members of the family of flavoenzyme pyridine nucleotide-disulfide reductases, which include glutathione reductase, trypanothione reductase, lipoamide dehydrogenase, and some other related enzymes (Williams, 1990; Arner et al., 2000; Nordberg et al., 2001). These NAD(P)H-dependent enzymes contain a flavin adenine dinucleotide (FAD) and a redoxactive disulfide in their active center. In the catalysis, the FAD accepts two electrons (hydride) from NAD(P) $\mathrm{H}$ and transfers it to the catalytic disulfide which subsequently reduces the disulfide oxidant. Importantly, there exist two groups of TRs, namely the low M.W. TR $(\sim 35 \mathrm{kD}, \mathrm{L}-\mathrm{TR})$ of plants, prokarya and many eukarya, which contain FAD and the catalytic disulfide (Williams, 1990; Lennon et al., 1999), and high m.w. TR ( $55 \mathrm{kD}$, $\mathrm{H}$-TR), which contain an additional redox-active $-\mathrm{Se}-\mathrm{S}$ moiety (mammalian TR), or an additional redox-active disulfide (Plasmodium spp.) (Arner et al., 2000; Nordberg et al., 2001; Kanzok et al., 2000). These additional redox groups of H-TR accept two redox equivalents from the reduced catalytic disulfide adjacent to FAD, and subsequently reduce the corresponding physiological disulfide oxidants.

Like other flavoenzymes-disulfide reductases, both L- and H-TRs reduce quinones and nitroaromatic compounds Vienožinskis et al., 1990; Čènas et al., 1994; 2004; 2006; Bironaitè et al., 1997; Miškinienè et al., 1998; and references therein). These reactions are of some biomedical importance, because the antioxidant disulfide reductases are considered potential targets of quinones and nitroaromatic compounds with respect to their potential anticancer, antimicrobial, and antiparasitic activities (C̈enas et al., 1994; 2004; 2006; and the references therein). The above compounds may act as „subversive substrates" for TRs, converting antioxidant functions into prooxidant ones due to redox-cycling reactions. In these cases, both H-TRs and L-TRs, e.g., L-TR of Trichomonas vaginalis, may be considered as potential redox-drug targets (Cènas et al., 2004; 2006; McMillan et al., 2009; and references therein). However, the reactions of L-TRs with quinones and nitroaromatic compounds have not been thoroughly studied so far, except for the Arabidopsis thaliana TR (Bironaite et al., 1997; Miškinienè et al., 1998).

Thermotoga maritima TR (Tm'TR, M.W. $34.3 \mathrm{kD}$ ) was the first TR isolated from a hyperthermophylic organism (Yang et al., 2009; Couturier et al., 2013). As the other L-TRs, it contains the NAD $(\mathrm{P}) \mathrm{H}$ binding motif, FAD, and the pair of active-site cysteines (McMillan et al., 2009). It participates in the antioxidant defence of $T$. maritima, providing electrons for peroxiredoxins via glutaredoxin-like proteins (Yang et al., 2009; Couturier et al., 2013). The catalytic mechanism of TmTR is not characterized so far.

In this paper, we provide a detailed analysis of the catalytic mechanism of $T$. maritima TR using a series of quinoidal and nitroaromatic electron acceptors. Apart from the quantitative structure-activity relationships in these reactions, our data enabled us to characterize the

e-mail: narimantas.cenas@bchi.vu.It

Abbreviations: $\mathrm{ArNO}_{2}$, aromatic nitrocompound; GR, glutathione reductase; Grx, glutaredoxin; $k_{\text {at' }}$ catalytic constant; $k_{\text {at }} / K_{\mathrm{m}^{\prime}}$ apparent bimolecular rate constant in steady-state enzymatic reactions; LipDH, lipoamide dehydrogenase; SOD, superoxide dismutase; TNT, 2,4,6-trinitrotoluene; TRx, thioredoxin; TR, thioredoxin reductase 
thermodynamic properties of TmTR involving the redox equilibrium with the $\mathrm{NAD}^{+} / \mathrm{NADH}$ couple.

\section{MATERIALS AND METHODS}

Enzymes and chemicals. T. maritima TR and Grx-1 were obtained as described (Couturier et al., 2013). The concentration of Tm'TR was determined according to the absorbance of FAD $\left(\varepsilon_{460}=10.9 \mathrm{mM}^{-1} \mathrm{~cm}^{-1}\right)$. Quinones, nitroaromatic compounds, NADH, NADPH, cytochrome $c$, and superoxide dismutase (SOD) were obtained from Sigma-Aldrich and Fluka. 2,4,6-Trinitrotoluene (TNT) and 2,4,6-trinitrophenyl- $N$-methylnitramine (tetryl) (a generous gift of Dr. Jonas Šarlauskas (Institute of Biochemistry, Vilnius)) were synthesized as described previously (Cènas et al., 2001). The synthesized compounds were characterized by their melting points, TLC, $1 \mathrm{H}$ NMR, UV, and IR spectroscopy and elemental analysis.

Steady-state kinetic studies. Steady-state kinetic measurements were performed spectrophotometrically by monitoring the oxidation of NADH $\left(\Delta \varepsilon_{340}=6.2\right.$ $\left.\mathrm{mM}^{-1} \mathrm{~cm}^{-1}\right)$ in the presence of TmTR and quinones or nitroaromatic compounds in $0.1 \mathrm{M}$ K-phosphate $(\mathrm{pH}$ 7.0) containing $1 \mathrm{mM}$ EDTA, at $25^{\circ} \mathrm{C}$ using Perkin Elmer Lambda 25 spectrophotometer. The initial rates of reaction were corrected for the intrinsic NADH oxidase activity of the enzyme, and for the nonenzymatic oxidation of NADH by 1,4-benzoquinone and 2-methyl-1,4benzoquinone, and for the spectral changes at $340 \mathrm{~nm}$ corresponding to reduction of nitrobenzenes (Nivinskas et al., 2001). The steady-state parameters of reactions, the catalytic constants $\left(k_{\text {cat }}\right)$ and the bimolecular rate constants $\left(k_{\text {cat }} / K_{\mathrm{m}}\right)$ of the oxidants at fixed concentration of NADH correspond to the reciprocal intercepts and slopes of Lineweaver-Burk plots, $[\mathrm{E}] / V$ vs. 1/[Q], where $V$ is the reaction rate, $[\mathrm{E}]$ is the enzyme concentration, and $[Q]$ is the concentration of quinone or nitroaromatic oxidant. $k_{\text {cat }}$ represents the number of molecules of $\mathrm{NADH}$ oxidized by a single active center of the enzyme per second. These parameters were obtained by the fitting of kinetic data to the parabolic expression using SigmaPlot 2000 (version 11.0, SPSS Inc.). Single-electron flux in the reduction of quinones was determined by monitoring 1,4-benzoquinone $(50 \mu \mathrm{M})$-mediated reduc-

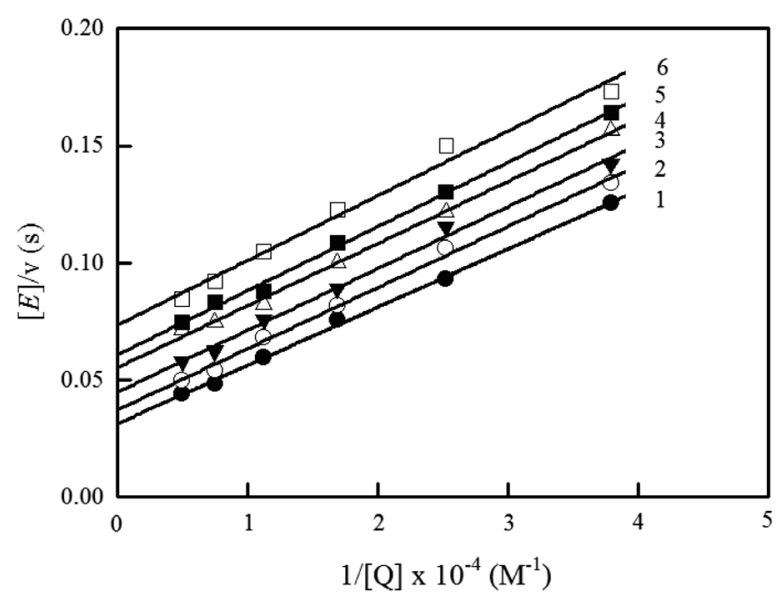

Figure 1. „Ping-pong" scheme of T. maritima TR catalyzed oxidation of NADH by 5,8-dihydroxy-1,4-naphtoquinone (naphthazarin).

NADH concentration was $100 \mu \mathrm{M}(1), 66.6 \mu \mathrm{M}(2), 44.4 \mu \mathrm{M}$ (3), 29.6 $\mu \mathrm{M}(4), 19.8 \mu \mathrm{M}(5)$, and $13.2 \mu \mathrm{M}(6)$. tion of cytochrome $c(50 \mu \mathrm{M})$ by TmTR in the presence of $100 \mu \mathrm{M}$ NADH assuming $\Delta \varepsilon_{550}=20 \mathrm{mM}^{-1} \mathrm{~cm}^{-1}$. The same conditions were used in the monitoring of TmTRmediated reduction of cytochrome $c$ by $50 \mu \mathrm{M}$ tetryl or $p$-dinitrobenzene in the presence of $100 \mu \mathrm{M}$ NADH and in the absence or presence of $100 \mathrm{U} / \mathrm{ml} \mathrm{SOD}$. Reduction rate of Grx-1 was monitored in the presence of 0.1 mM DTNB assuming $\Delta \varepsilon_{412}=27.2 \mathrm{mM}^{-1} \mathrm{~cm}^{-1}$.

Presteady-state kinetic measurements. The presteady-state kinetic measurement of reduction of TR by excess NADH was carried out in $0.1 \mathrm{M} \mathrm{K}$-phosphate buffer containing $1 \mathrm{mM}$ EDTA at $\mathrm{pH} 7.0$ and $25^{\circ} \mathrm{C}$ using a stopped-flow SX.17 MV spectrophotometer (Applied Photophysics). The final concentration of the enzyme was $5.0 \mu \mathrm{M}$. Because of the low NADH oxidase activity of $\operatorname{Tm} T r, 0.05 \mathrm{~s}^{1}$, which could marginally affect the data of the measurements, the experiments were performed under aerobic conditions. The kinetics of absorbance decrease at $460 \mathrm{~nm}$ was analyzed according to the single exponent fit using SigmaPlot software.

Amino acid sequence alignment. Amino acid sequence alignment of TmTR and related enzymes was performed using Clustal Omega software (www.ebi. ac.uk/Tools/msa/clustalo/).

\section{RESULTS}

\section{Steady-state reactions of $T$. maritima TR}

The physiological electron acceptors of $T$. maritima TR are poorly characterized except for glutaredoxin-1 (Grx-1) (McMillan et al., 2009; Yang et al., 2009), which also possesses a relatively low activity. The maximal rate of Grx-1 reduction at $\mathrm{pH} 7.0$ (0.1 M K-phosphate, $100 \mu \mathrm{M}$ NADH, 3-10 $\mu \mathrm{M}$ Grx-1) using the DTNB assay was $0.2-0.3 \mathrm{~s}^{-1}$, which is close to the intrinsic NADH oxidase activity of the enzyme, $0.05 \mathrm{~s}^{-1}$. In agreement with the previous data (Yang et al., 2009), an increase in $\mathrm{pH}$ to $8.0(0.03 \mathrm{M}$ Tris- $\mathrm{HCl})$ increased the reactivity of Grx-1. Under these conditions, $k_{\text {cat }}$ was equal to $2.1 \pm 0.6 \mathrm{~s}^{-1}$, and the $k_{\text {cat }} / K_{\mathrm{m}}$ for Grx-1 was $6.3 \pm 0.6 \times 10^{5}$ $\mathrm{M}^{-1} \mathrm{~s}^{-1}$.

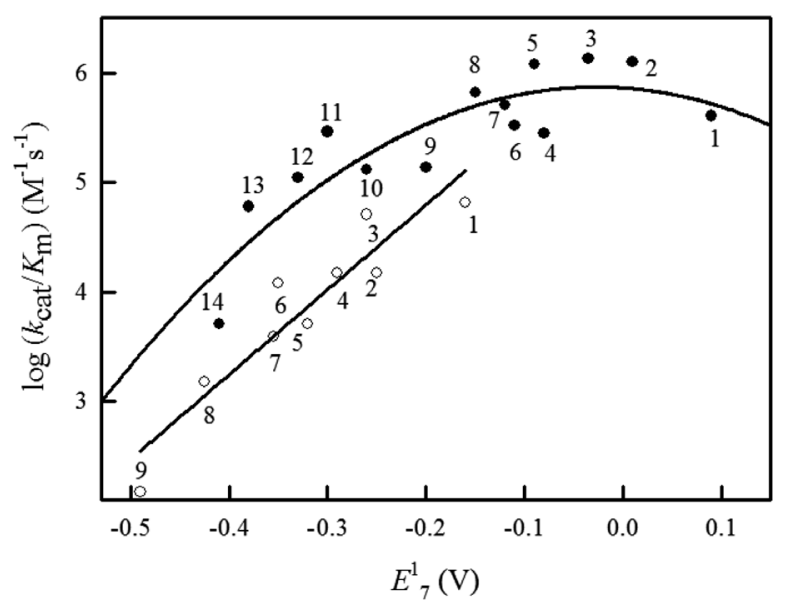

Figure 2. Reactivity of quinones and nitroaromatic compouns in $T$. maritima TR-catalyzed reactions.

Relationship between log $k_{\mathrm{cat}} / K_{\mathrm{m}}$ of quinones (solid circles) and nitroaromatic compounds (blank circles) in TmTR catalyzed reaction and their single-electron reduction potentials at $\mathrm{pH} 7.0\left(\mathrm{E}^{1}\right)$ is shown. Numbers refer to quinones and nitroaromatic compounds whose redox potentials and reduction rate constants are given in Table 1. 
Table 1. Kinetic parameters of reduction of quinones and nitroaromatic compounds by $T$. maritima thioredoxin reductase.

The catalytic constants $\left(k_{\text {cat }}\right)$ and bimolecular rate constants $\left(k_{\text {cat }} / K_{\mathrm{m}}\right)$ of electron acceptors in TmTR catalyzed reactions at pH 7.0 and $25^{\circ} \mathrm{C}$ were obtained in the presence of $100 \mu \mathrm{M}$ NADH. Their single-electron reduction potentials at $\mathrm{pH} 7.0\left(E_{7}^{1}\right)$ are taken from Wardman (1989), and Šarlauskas et al., (2006).

\begin{tabular}{|c|c|c|c|c|}
\hline No & Compound & $E^{1}(\mathrm{~V})$ & $k_{\text {cat }}\left(\mathrm{s}^{-1}\right)$ & $k_{\mathrm{cat}} / K_{\mathrm{m}}\left(\mathrm{M}^{-1} \mathrm{~s}^{-1}\right)$ \\
\hline & Quinones & & & \\
\hline 1 & 1,4-Benzoquinone & 0.09 & $35.7 \pm 3.4$ & $(4.05 \pm 0.5) \times 10^{5}$ \\
\hline 2 & 2-Methyl-1,4-benzoquinone & 0.01 & $19.8 \pm 2.2$ & $(1.26 \pm 0.15) \times 10^{6}$ \\
\hline 3 & 2,3-Dichloro-1,4-naphthoquinone & -0.035 & $56.4 \pm 6.5$ & $(1.35 \pm 0.14) \times 10^{6}$ \\
\hline 4 & 2,6-Dimethyl-1,4-benzoquinone & -0.08 & $35.4 \pm 4.5$ & $(2.79 \pm 0.3) \times 10^{5}$ \\
\hline 5 & 5-Hydroxy-1,4-naphthoquinone & -0.09 & $47.7 \pm 6.0$ & $(1.2 \pm 0.13) \times 10^{6}$ \\
\hline 6 & 5,8-Dihydroxy-1,4-naphthoquinone & -0.11 & $29.1 \pm 3.2$ & $(3.3 \pm 0.4) \times 10^{5}$ \\
\hline 7 & 9,10-Phenanthrenequinone & -0.12 & $58.5 \pm 4.8$ & $(5.1 \pm 0.45) \times 10^{5}$ \\
\hline 8 & 1,4-Naphthoquinone & -0.15 & $18.9 \pm 1.8$ & $(6.6 \pm 0.8) \times 10^{5}$ \\
\hline 9 & 2-Methyl-1,4-naphthoquinone & -0.20 & $24.6 \pm 3.7$ & $(1.38 \pm 0.15) \times 10^{5}$ \\
\hline 10 & Tetramethyl-1,4-benzoquinone & -0.26 & $3.9 \pm 0.4$ & $(1.3 \pm 0.11) \times 10^{5}$ \\
\hline 11 & 1,4-Dihydroxy-9,10-anthraquinone & -0.30 & $2.9 \pm 0.2$ & $(2.9 \pm 0.3) \times 10^{5}$ \\
\hline 12 & 1,8-Dihydroxy-9,10-anthraquinone & -0.33 & $1.5 \pm 0.2$ & $(1.1 \pm 0.12) \times 10^{5}$ \\
\hline 13 & 9,10-Anthraquinone-2-sulfonic acid & -0.38 & $0.96 \pm 0.2$ & $(6.0 \pm 0.5) \times 10^{4}$ \\
\hline \multirow[t]{2}{*}{14} & 2-Hydroxy-1,4-naphthoquinone & -0.41 & $0.75 \pm 0.1$ & $(5.1 \pm 0.45) \times 10^{3}$ \\
\hline & Aromatic nitrocompounds & & & \\
\hline 1 & 2,4,6-Trinitrophenylmethylnitramine (tetryl) & -0.16 & $6.3 \pm 0.6$ & $(6.6 \pm 0.7) \times 10^{4}$ \\
\hline 2 & 2,4,6-Trinitrotoluene & -0.25 & $4.2 \pm 0.4$ & $(1.5 \pm 0.2) \times 10^{4}$ \\
\hline 3 & 1,4-Dinitrobenzene & -0.26 & n.d. & $(5.1 \pm 0.4) \times 10^{4}$ \\
\hline 4 & 1,2-Dinitrobenzene & -0.29 & $4.2 \pm 0.3$ & $(1.5 \pm 0.1) \times 10^{4}$ \\
\hline 5 & 4-Nitrobenzaldehyde & -0.32 & n.d. & $(5.1 \pm 0.45) \times 10^{3}$ \\
\hline 6 & 1,3-Dinitrobenzene & -0.35 & $2.4 \pm 0.25$ & $(1.2 \pm 0.2) \times 10^{4}$ \\
\hline 7 & 4-Nitroacetophenone & -0.355 & $5.1 \pm 0.4$ & $(3.9 \pm 0.5) \times 10^{3}$ \\
\hline 8 & 4-Nitrobenzoic acid & -0.425 & $1.8 \pm 0.3$ & $(1.5 \pm 0.1) \times 10^{3}$ \\
\hline 9 & Nitrobenzene & -0.49 & $0.4 \pm 0.05$ & $150 \pm 20$ \\
\hline
\end{tabular}

In contrast, the TmTR-catalyzed oxidation of NADH by a number of quinones and nitroaromatic compounds at $\mathrm{pH} 7.0$ was much faster (Table 1). Using varied concentrations of 5,8-dihydroxy-1,4-naphthoquinone (naphthazarin) as an electron acceptor at several fixed concentrations of $\mathrm{NADH}$, the reaction was characterized by a series of parallel Lineweaver-Burk plots (Fig. 1). It corresponds to a ,ping-pong" scheme, which was also characteristic for the quinone- and nitroreductase reactions of $A$. thaliana TR (Bironaite et al., 1997; Miškiniene et al., 1998). In our case, $k_{\text {cat }} / K_{\mathrm{m}}$ for naphtazarin was $3.3 \pm 0.3 \times 10^{5} \mathrm{M}^{-1} \mathrm{~s}^{-1}$, the $k_{\text {cat }} / K_{\mathrm{m}}$ for $\mathrm{NADH}$ was $1.7 \pm 0.2 \times 10^{6} \mathrm{M}^{-1} \mathrm{~s}^{-1}$, and $k_{\text {cat }}$, obtained by extrapolation to infinite concentrations of $\mathrm{NADH}$ and napthhazarin, was equal to $39.1 \pm 3.5 \mathrm{~s}^{-1}$.
The studies of quinone and nitroaromatic $\left(\mathrm{ArNO}_{2}\right)$ electron acceptors revealed that the reactivity of compounds $\left(\log k_{\text {cat }} / K_{\mathrm{m}}\right)$ generally increased with an increase in their single-electron reduction potential $\left(E_{7}^{1}\right)$, i.e., the potential of the quinone/semiquinone or $\mathrm{ArNO}_{2} /$ $\mathrm{ArNO}_{2}{ }^{-}$redox couples (Fig. 2). The reactivity of nitroaromatics was systematically lower than that of quinones with similar $E^{1}$, values (Fig. 2).

Next we aimed at characterizing the possible singleelectron transfer events in the reduction of quinones and nitroaromatics by $T$. maritima TR. The percentage of the single-electron flux in the reduction of quinones by NAD(P)H-oxidizing flavoenzymes can be determined using 1,4-benzoquinone-mediated reduction of added cytochrome c (Iyanagi et al., 1990, 


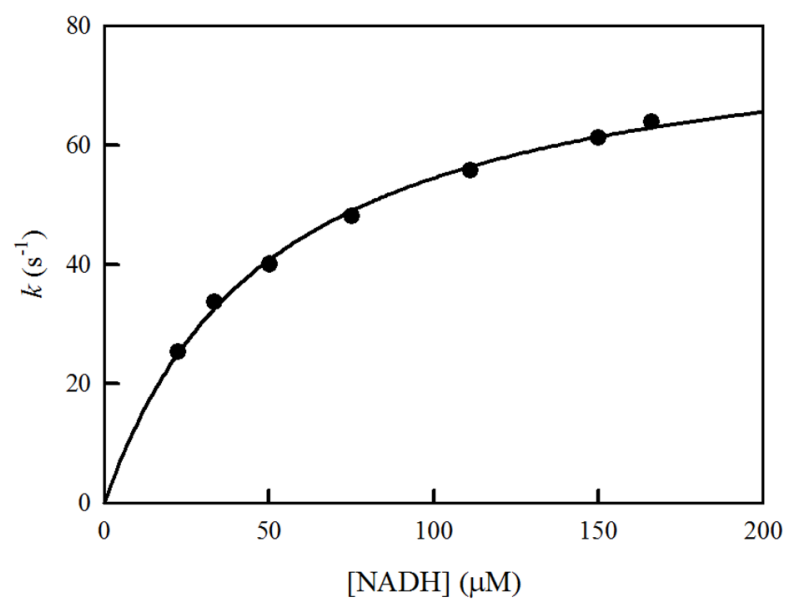

Figure 3. Presteady-state reduction of TmTR by NADH monitored at $460 \mathrm{~nm}$.

The dependence of pseudofirst-order presteady-state reduction rate constant $(k)$ of reduction of TmTR on NADH concentration is shown.

and references therein), and it is equal to the ratio between the cytochrome $c$ reduction rate and a doubled rate of $\mathrm{NAD}(\mathrm{P}) \mathrm{H}$ oxidation. This is based on the fact that at $\mathrm{pH}<7.2$ the rate of reduction of cytochrome $c$ by 1,4-hydroquinone is negligible, whereas 1,4-benzosemiquinone, formed during the single-electron reduction, reduces cytochrome $c$ at a high rate $\left(\mathrm{k} \approx 10^{6} \mathrm{M}^{-1} \mathrm{~s}^{-}\right.$ 1) (Iyanagi, 1990). During the TmTR-catalyzed reduction of $50 \mu \mathrm{M}$ 1,4-benzoquinone by $150 \mu \mathrm{M}$ NADH, the rate of reduction of added $50 \mu \mathrm{M}$ cytochrome $c$ was equal to $50 \%$ of $\mathrm{NADH}$ oxidation rate. This shows that single-electron flux makes up $25 \%$ of the overall electron flux in this case. The quantitation of single-electron flux in the nitroreductase reactions of flavoenzymes is less straightforward, because both nitroaromatic anion-radicals and the products of their two(four)-electron reduction (hydroxylamines) reduce cytochrome c (Šarlauskas et al., 2004). During the TmTR-catalyzed oxidation of $100 \mu \mathrm{M}$ NADH by $100 \mu \mathrm{M} p$-dinitrobenzene, the rate of reduction of added $50 \mu \mathrm{M}$ cytochrome $c$ was $160 \%$ of $\mathrm{NADH}$

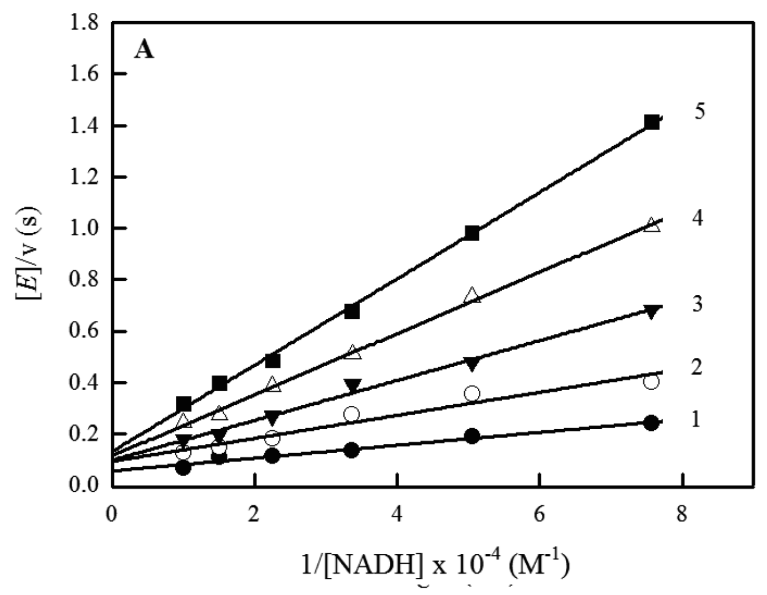

oxidation rate. The cytochrome $c$ reduction was inhibited by $100 \mathrm{U} / \mathrm{mg}$ superoxide dismutase (SOD) by $25 \%$. In this case, the $\mathrm{ArNO}_{2} / \mathrm{ArNO}_{2}$ and $\mathrm{O}_{2}^{-} \cdot \mathrm{O}_{2}^{-} \cdot$ redox couples are under rapid equilibrium, and only the $\mathrm{O}_{2}^{-\bullet}$-mediated, but not the nitroradical-mediated, cytochrome $c$ reduction is inhibited by SOD. Nevertheless, it points to an at least $20 \%$ share of singleelectron flux in the reduction of nitroaromatic compounds by TmTR.

It is commonly accepted that quinoidal compouds are reduced by the reduced FAD of flavoenzymes containing a catalytic disulfide (Vienožinskis et al., 1990; Čènas et al., 1994; 2004; 2006; Bironaitè et al., 1997; Miškiniené et al., 1998; and references therein). This may also be true for TmTR, because a 40-50 min-incubation of the reduced enzyme with the thiolalkylating agent $p$-chloromercury benzoate ( $p$-CMB) $(200 \mu \mathrm{M}$ NADH and $100 \mu \mathrm{M} p$-CMB) resulted in a $95 \%$ inhibition of the reduction of Grx-1 $(4.0 \mu \mathrm{M})$. In contrast, the reduction of $100 \mu \mathrm{M}$ naphthazarin was inhibited by $40-50 \%$. In control experiments, incubation of TrxR with $200 \mu \mathrm{M}$ NADH resulted in the inhibition of Grx-1 and naphthazarin reduction activity by $10-15 \%$. It shows that reduced thiol groups do not participate in the reduction of quinones. Because the reduction of quinones and nitroaromatics involves a single-electron transfer step, this selectivity may be caused by the high endothermicity of a single-electron transfer from the dithiol moiety, i.e., the high redox potential of the thiyl radical/thiol redox couple, $\sim 1.0 \mathrm{~V}$ (Wardman, 1990).

\section{Presteady-state reactions of $T$. maritima TR}

The preliminary prestady-state measurements of reduction of TR by excess NADH monitored at 460 $\mathrm{nm}$ show that the kinetics of the reaction are best described by a single-exponent fit. The reduction of FAD is characterized by a maximal rate of $82 \pm 3.0 \mathrm{~s}^{-1}$, and the apparent bimolecular rate constant of TmTR reduction by $\mathrm{NADH}, 1.6 \pm 0.15 \times 10^{6} \mathrm{M}^{-1} \mathrm{~s}^{-1}$ (Fig. 3). The latter value is close to the $k_{\text {cat }} / K_{\mathrm{m}}$ for NADH, obtained in the steady-state experiments (Fig. 1). Typically, the absorbance of FAD at $460 \mathrm{~nm}$ decreased by $70-80 \%$ at the end of the reaction, as in the case of E. coli TR (Lennon et al., 1997).

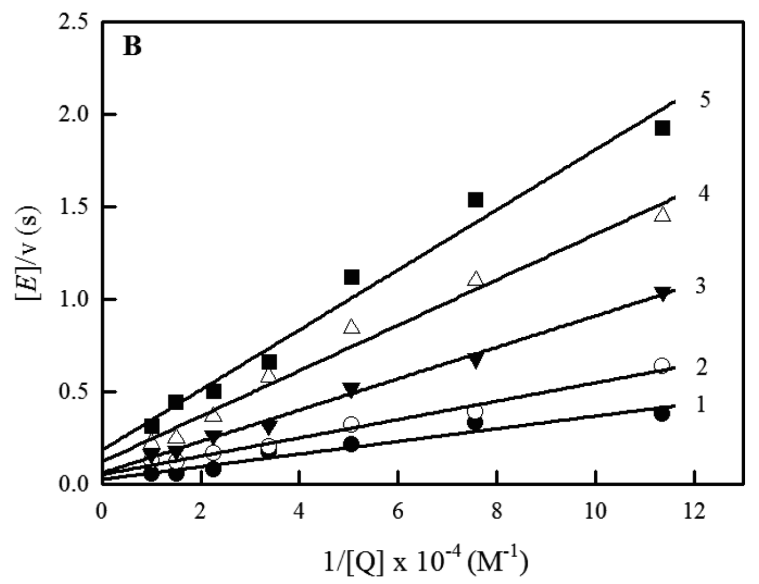

Figure 4. Inhibition of TmTR by NAD+.

(A) TmTR quinone reductase reaction inhibition by NAD+ at varied NADH concentrations in the presence of $100 \mu \mathrm{M}$ naphtazarin. NAD+ concentrations: $0 \mathrm{mM}$ (1), $0.2 \mathrm{mM}(2), 0.4 \mathrm{mM}(3), 0.6 \mathrm{mM}(4)$, and $1.0 \mathrm{mM}$ (5). (B) TmTR quinone reductase reaction inhibition by NAD+ at varied naphthazarin concentrations in the presence of $100 \mu \mathrm{M}$ NADH. NAD+ concentrations: $0 \mathrm{mM}(1), 0.2 \mathrm{mM}(2), 0.4 \mathrm{mM}(3), 0.6 \mathrm{mM}(4)$, and $1.0 \mathrm{mM}(5)$. 

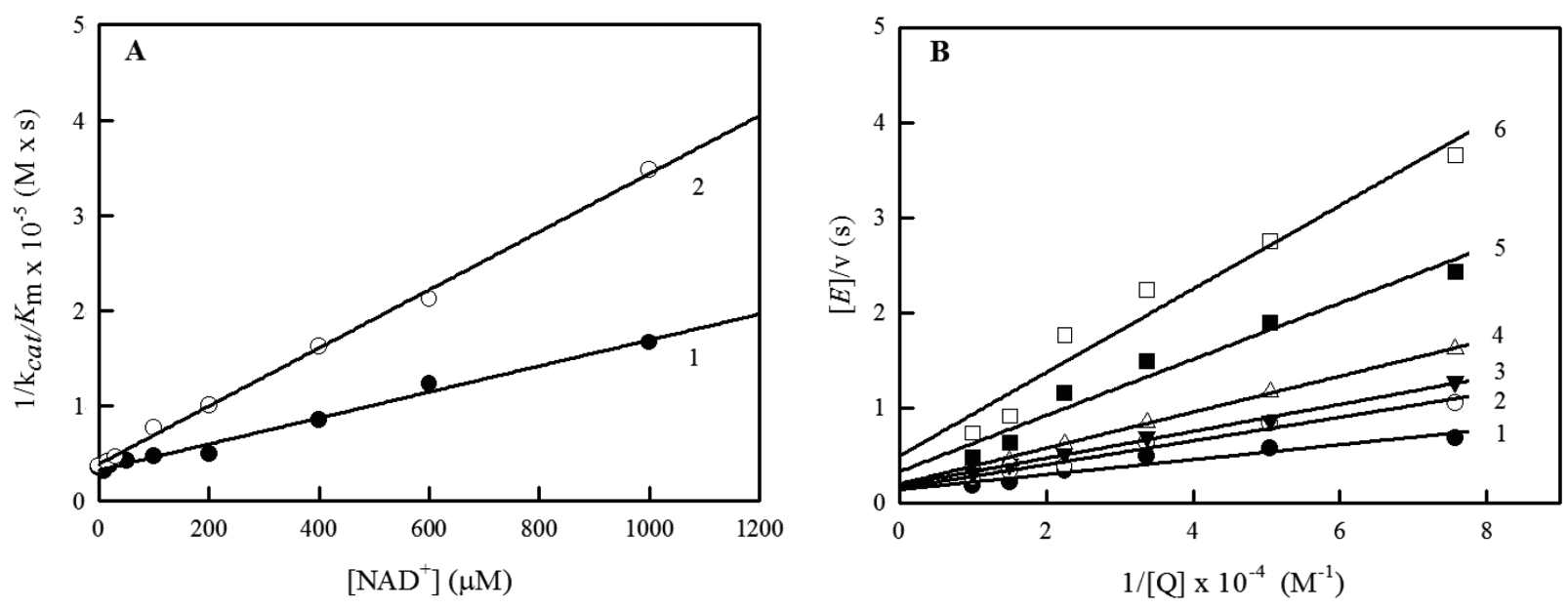

Figure 5. Inhibition of TmTR by NAD+.

(A) Decrease of naphthazarin $k_{c a d} / K_{m}$ by $\mathrm{NAD}^{+}$at $[\mathrm{NADH}]=100 \mu \mathrm{M}(1)$, and $[\mathrm{NADH}]=30 \mu \mathrm{M}(2)$; (B) Influence of $600 \mu \mathrm{M} \mathrm{NAD}^{+}$on rate of TmTR-catalyzed oxidation of NADH by naphthazarin. NADH concentrations: $100 \mu \mathrm{M}$ (1), $66.6 \mu \mathrm{M}(2), 44.4 \mu \mathrm{M}(3), 29.6 \mu \mathrm{M}(4), 19.8 \mu \mathrm{M}(5)$, $13.2 \mu \mathrm{M}(6)$.

\section{Inhibition of quinone reductase reaction of TmTR by NAD ${ }^{+}$}

The inhibition of NAD(P)H-oxidizing flavoenzymes by the reaction product, $\mathrm{NAD}(\mathrm{P})^{+}$, gives some information on the binding of $\mathrm{NAD}(\mathrm{P}) \mathrm{H} / \mathrm{NAD}(\mathrm{P})^{+}$to the different redox states of the enzyme, and, in certain cases, on its redox equilibrium with the $\mathrm{NAD}(\mathrm{P})^{+} / \mathrm{NAD}(\mathrm{P}) \mathrm{H}$ couple (Vienožinskis et al., Bironaite et al., 1997; Ċenas et al., 2004). In the case of T. maritima TR, NAD ${ }^{+}$acted as a mixed-type inhibitor towards NADH (Fig. 4A), i.e., it decreased both the maximal rate of the reaction and the $k_{\mathrm{cat}} / K_{m}$ for NADH. This means that $\mathrm{NAD}^{+}$not only competes with NADH for the binding to the oxidized enzyme form, but also competes with the quinoidal electron acceptor for the binding to the reduced enzyme form, or even reoxidizes the reduced enzyme (Rudolph et al., 1979). In agreement with this, $\mathrm{NAD}^{+}$acts as a mixed-type inhibitor towards naphthazarin (Fig. 4B), decreasing both its $k_{\text {cat }} / K_{\mathrm{m}}$ and the maximal reaction rate. Importantly, the inhibitory effect of $\mathrm{NAD}^{+}$towards the $k_{\text {cat }} / K_{\mathrm{m}}$ of naphthazarin decreased with an increase in $\mathrm{NADH}$ concentration from $30 \mu \mathrm{M}$ to $100 \mu \mathrm{M}$ (Fig. 5A). Besides, in the presence of $600 \mu \mathrm{M} \mathrm{NAD}^{+}$, varied naphthazarin concentrations at several fixed concentrations of NADH give a series of converging Lineweaver-Burk plots (Fig. 5B). This is in contrast with the series of parallel double-reciprocal plots obtained in the absence of $\mathrm{NAD}^{+}$(Fig. 1). Thus, based on the general effects of the reaction products on the reaction rates (Rudolph \& Fromm, 1979; Rudolph, 1979), the data of Fig. 5A, $\mathrm{B}$ indicate that $\mathrm{NAD}^{+}$not only competes with naphthazarin for the binding to the reduced enzyme, but also reoxidizes the reduced enzyme at a rate comeasurable

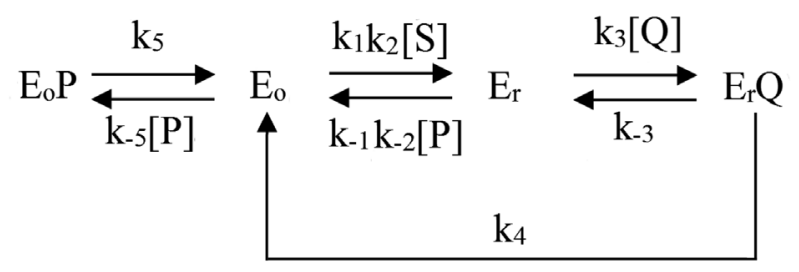

Scheme 1

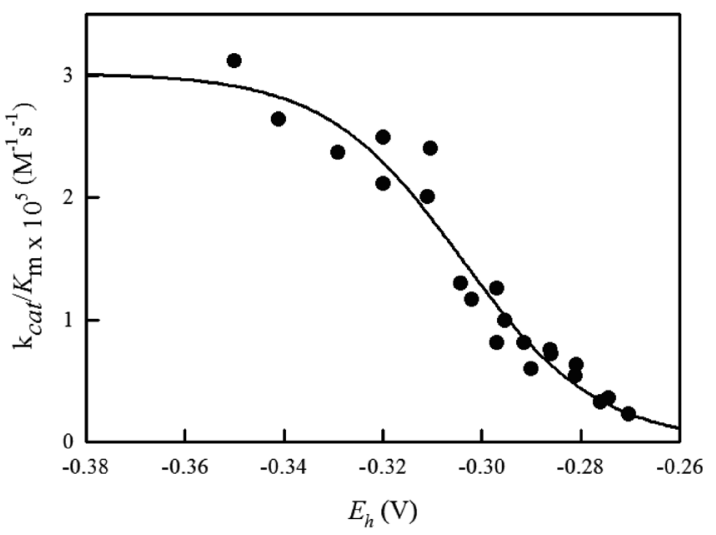

Figure 6. Dependence of TmTR activity on [NAD+]/[NADH] ratio. Dependence of $k_{\text {cat }} / K_{\mathrm{m}}$ of naphthazarin on the redox potential of medium $\left(E_{\mathrm{h}}\right)$ at $\mathrm{pH} 7.0$, i.e. [NAD+]/[NADH] ratio.

with the forward reaction, i.e., the reduction of the oxidized enzyme by NADH (Rudolph et al., 1979; Rudolph, 1979). Taken together, the data of Fig. 1, 4A, B, and 5A, $\mathrm{B}$ enable us to present a general scheme of quinone reduction by T. maritima TR (Scheme 1). Assuming a rapid equilibrium between the oxidized $\left(\mathrm{E}_{\mathrm{o}}\right)$ and reduced $\left(\mathrm{E}_{\mathrm{r}}\right)$ enzyme forms and $\mathrm{NADH}(\mathrm{S})$ and $\mathrm{NAD}^{+}(\mathrm{P})$, Scheme 1 gives the following steady-state rate equation (Eqn. 1), where $\mathrm{Q}$ is the electron acceptor:

$$
\frac{[E]}{V}=\frac{1}{k_{4}}+\left(1+\frac{k_{-3}}{k_{4}}\right)\left(\frac{1}{k_{3}[Q]}+\frac{k_{-1} k_{-2} k_{-5}[P]^{2}}{k_{1} k_{2} k_{3} k_{5}[S][Q]}+\frac{k_{-1} k_{-2}[P]}{k_{1} k_{2} k_{3}[S][Q]}\right)+\frac{1}{k_{1} k_{2}[S]}\left(1+\frac{k_{-5}[P]}{k_{5}}\right)(1)
$$

In the absence of $\mathrm{NAD}^{+}([\mathrm{P}]=0)$, Eqn. 1 is reduced to Eqn. 2, which corresponds to a simple „ping-pong“" scheme:

$$
\frac{[E]}{V}=\frac{1}{k_{4}}+\left(1+\frac{k_{-3}}{k_{4}}\right) \frac{1}{k_{3}[Q]}+\frac{1}{k_{1} k_{2}[S]}
$$

Importantly, Eqn. 1 shows that the $k_{\text {cat }} / K_{\mathrm{m}}$ of reduction of quinone $\left(k_{3} k_{4} /\left(k_{-3}+k_{4}\right)\right)$ should decrease with an increase in the $[\mathrm{P}] /[\mathrm{S}]$ ratio (i.e., the $\left[\mathrm{NAD}^{+}\right] /[\mathrm{NADH}]$ ratio) which, in the case of the rapid redox equilibrium, corresponds to the redox potential of the medium, $E_{h}$. 
We summarized the data from Fig. 4A, B, and 5A, B in Fig. 6, expressing $k_{\text {cat }} / K_{\mathrm{m}}$ for naphthazarin as a function of $E_{h}$, and taking the standard redox potential for $\left[\mathrm{NAD}^{+}\right] /[\mathrm{NADH}]$ couple as $-0.32 \mathrm{~V}$. The data of Fig. 6 show that $50 \%$ inhibition of quinone reductase activity expressed as $k_{\text {cat }} / K_{\mathrm{m}}$ takes place at $E_{\mathrm{h}}=-0.31 \pm 0.03 \mathrm{~V}$.

\section{DISCUSSION}

In comparison with other L-TRs, the redox properties of TmTR are incompletely characterized so far, although some data point to the similarity of its properties to those of previously studied homologues. The sequence of TmTR (Genbank accession number TM_0869 or AAD35951) shows that its catalytic disulfide motif (Cys147, Ala-148, Thr-149, and Cys-150) which likely participates in the reduction of glutaredoxin-1 is similar to that of E. coli TR, which reduces thioredoxins (Lennon et al., 1999). The interdomain sequence motifs of E. coli TR (Gly-244, Pro-247) and A. thaliana TR (Gly-298, Pro301 ) correspond to Gly-251 and Pro-254 in T. maritima TR. These data indirectly point to a possible similarity in the catalysis of those TRs, involving a transition between the flavin-to-disulfide- and flavin-to-NAD $(\mathrm{P}) \mathrm{H}$-binding site conformations (Dai et al., 1996; Lennon et al., 1997, 1999).

In this study, we aimed to characterize the redox properties of T. maritima TR, using quinones and nitroaromatic compounds as nopnphysiological oxidants. The comparison of presteady- and steady-state kinetic data of the enzyme (Fig. 1, 3, Table 1) shows that the oxidative half-reaction is rate-limiting in the catalysis, with a possible exception of 2,3-dichloro-1,4-naphthoquinone, 5-hydroxy-1,4-naphthoquinone, and 9,10-phenanthrene quinone, where the reductive reaction may be partly rate-limiting.

There are also other similarities in the action of TmTR and $A$. thaliana TR, namely the mixed singleand two-electron reduction of quinones and nitroaromatics, which follow parabolic dependences of $\log k_{\text {cat }} /$ $K_{m}$ on their $E^{1}{ }_{7}$ (Table 1, Fig. 2) (Bironaite et al., 1997; Miškiniene et al., 1998) This is in line with an "outersphere" electron transfer pathway (Marcus and Sutin,1985), or with a mixed one- and two-electron transfer $\left(e^{-}, \mathrm{H}^{+}, e^{-}\right)$with a rate limiting first electron transfer (Anusevičius et al., 2005). In this case, the systematic lower reactivity of nitroaromatic compounds may be attributed to their lower single-electron self-exchange rate constant $\left(\sim 10^{5} \mathrm{M}^{-1} \mathrm{~s}^{-1}\right)$ (Meotner et al., 1986), in comparison to that of quinones $\left(\sim 10^{8} \mathrm{M}^{-1} \mathrm{~s}^{-1}\right)$ (Grampp et al., 1987). These reactions contrast with the physiological reactions of L-TRs, the obligatory net two-electron (hydride) transfer from $\mathrm{NAD}(\mathrm{P}) \mathrm{H}$ to the disulfide oxidant. Nevertheless, the data on quinone- and nitroreductase reactions of $T$. maritima and $A$. thaliana L-TRs complement each other (Miškinienè et al., 1998) and show that the single-electron transfer is feasible in this group of pyridine nucleotide-disulfide reductases. It is indirectly supported by the stabilization of the neutral flavin semiquinone of $E$. coli TrxR under photoirradiation conditions (Zanetti et al., 1968). We suppose that these reactions may contribute to the prooxidant cytotoxicity of these compounds.

However, there are also some differences between the reactions of $T$. maritima and $A$. thaliana TRs. First, the quinone reductase reaction of $A$. thaliana TR is characterized by a competitive inhibition of $\mathrm{NADP}^{+} v s$. NADPH, and by an uncompetitive inhibition of $\mathrm{NADP}^{+} v$ s. the quinone oxidant (Bironaite et al., 1997). Besides, in the presence of $\mathrm{NADP}^{+}$, the "ping-pong" scheme of quinone reduction was unchanged, i.e., it was not converted into a series of converging double-reciprocal plots, like in Fig. 5B. This is in line with the low oxidation rate of reduced $A$. thaliana TR by $\mathrm{NADP}^{+}$, and the previously established $\mathrm{E}^{0}{ }_{7}$ of FAD of $A$. thaliana TR, $-0.244 \mathrm{~V}$ (Bironaite et al., 1997). In contrast, the inhibition of Tm'TR by $\mathrm{NAD}^{+}$(Fig. 4A, B, 5A, B) corresponds to the rapid establishment of the redox equilibrium between TR and $\mathrm{NAD}^{+} / \mathrm{NADH}$ (Scheme 1, Eqn. 1), thus pointing to a lower redox potential of FAD. The dependence of $k_{\text {cat }} / K_{\mathrm{m}}$ of naphthazarin on the $\left[\mathrm{NAD}^{+}\right] /[\mathrm{NADH}] \mathrm{ra}-$ tio (Fig. 6) shows that the $E^{0}{ }_{7}$ value of the FAD cofactor of $T$. maritima TR may be equal to $-0.31 \pm 0.03 \mathrm{~V}$. This value may be taken as realistic, because it is close to the redox potential of the catalytic disulfide, -0.295 V (Couturier et al., 2013). Similar small differences between the $\mathrm{E}_{7}^{0}$ values of $\mathrm{FAD}$ and the catalytic disulfide, about $0.02 \mathrm{~V}$, were observed in potentiometric studies of E. coli L-TR (Williams, 1990).

In conclusion, our study preliminarily assessed the previously uncharacterized redox and kinetic properties of T. maritima L-TR. This enzyme, like the previously studied $A$. thaliana TR, may be considered as a potential target for redox active herbicides like 2,3-dichloro-1,4-naphthoquinone, the air pollution agent 9,10-phenanthrene quinone, and the explosives tetryl and TNT (Table 1), which are important soil and groundwater pollutants at their disposal sites (Bironaite et al., 1997; Miškinienè et al., 1998; and references therein). These compounds may be considered as the "subversive substrates" for T. maritima TR because they convert the antioxidant functions of this enzyme into prooxidant ones due to their redox cycling. These reactions may be important in their action against $T$. maritima which, although anaerobic, can proliferate under low $\mathrm{O}_{2}$ tension as well, and suffer from oxidative stress (Lefourn et al., 2008). These features may be even more important in view of the recently emerged interest in the use of T. maritima spp. in food, paper, and biofuel-related applications (Frock et al., 2010).

\section{REFERENCES}

Anusevičius Ž, Misevičienė L, Medina M, Martinez-Julvez M, GomezMoreno C, Ċenas N (2005) FAD semiquinone stabiliy regulates single- and two-electron reaction od quinones by Anabaena PCC7119 ferredoxin:NADP ${ }^{+}$reductase and its Glu301Ala mutant. Arch Biochem Biophys 437: 144-150.

Arner ESI, Holmgren A (2000) Physiological functions of thioredoxin and thioredoxin reductase. Eur J Biochem 267: 6102-6109.

Bironaite D, Anusevičius Ž, Jacquot JP, Č̉nas N (1997) Interaction of quinones with Arabidopsis thaliana thioredoxin reductase. Biochim Biophys Acta 1383: 82-92.

Čènas N, Nemeikaitè-Čènienè A, Sergedienè E, Nivinskas H, Anusevičius Ž, Šarlauskas J (2001) Quantitative structure-activity relationships in enzymatic single-electron reduction of nitroaromatic explosives: implications for their cytotoxicity. Biochim Biophys Acta 1528: $31-38$.

Čènas N, Nivinskas H, Anusevičius Ž, Šarlauskas J, Lederer F, Arner ESJ (2004) Interactions of quinones with thioredoxin reductase. A challenge to the antioxidant role of the mammalian selenoprotein. $J$ Biol Chem 279: 2583-2592.

Čènas N, Prast S, Nivinskas H, Šarlauskas J, Arner ESJ (2006) Interactions of nitroaromatic compounds with the mammalian selenoprotein thioredoxin reductase and the relation to induction of apoptosis in human cancer cells. I Biol Chem 281: 5593-5603.

Čenas NK, Arscott D, Williams CH Jr, Blanchard JS (1994) Mechanism of reduction of quinones by Trypanosoma congolense trypanothione reductase. Biochemistry 33: 2509-2515.

Couturier J, Prosper P, Winger AM, Hecker A, Hirasawa M, Knaff DB, Gans P, Jacquot JP, Navaza A, Haouz A, Rouhier N (2013) In the absence of thioredoxins, what are the reductants for peroxiredoxins in Thermotoga maritima? Antioxidants Redox Signall 18: 16131622. 
Dai S, Saarinen M, Ramaswamy S, Meyer Y, Jacquot J-P, Eklund H (1996) Crystal structure of Arabidopsis thaliana NADPH dependent thioredoxin reductase at $2.5 \AA$ resolution. J Mol Biol 264: 1044-1057.

Frock AD, Notey JS, Kelly RM (2010) The genus Thermotoga: recent developments. Environ Technol 31: 1169-1181.

Grampp G, Jaenicke W (1987) ESR-spectroscopic investigation of the parallel electron and proton exchange between quinones and their radicals: Part I. Measurements at 298 K. J Electroanal Chem 229: 297-303.

Iyanagi T (1990) On the mechanism of one-electron reduction of quinones by microsomal flavin enzymes: the kinetic analysis between cytochrome $\mathrm{b}_{5}$ and menadione. Free Radic Res Commun 8: 259-268.

Jacquot JP, Eklund H, Rouhier N, Schürmann P (2009) Structural and evolutionary aspects of thioredoxin reductases in photosynthetic organisms. Trends Plant Sci 14: 336-343.

Kanzok SM, Schirmer RH, Turbachova I, Iozef R, Becker K (2000) The thioredoxin system of the malaria parasite Plasmodium falciparum. Glutathione reduction revisited. I Biol Chem 275: 40180-40186.

LeFourn C, Fardeau ML, Olivier B, Lojou E, Dolla A (2008) The hyperthermophylic anaerobic Thermotoga maritima is able to cope with limited amount of oxygen. Insight of the defence strategies. Environ Microbiol 10: 1877-1887.

Lennon BW, Williams CH Jr (1997) Reductive half-reaction of thioredoxin reductase from E. coli. Biochemistry 36: 9464-9477.

Lennon BW, Williams CH Jr, Ludwig ML (1999) Crystal structure of reduced thioredoxin reductase from Escherichia coli: Structural flexibility in the isoalloxazine ring of the flavin adenine dinucleotide cofactor. Protein Sci 8: 2366-2379.

Marcus RA, Sutin N (1985) Electron transfers in chemistry and biology. Biochim Biophys Acta 811: 265-322.

McMillan PJ, Patzewitz EM, Young SE, Westrop GD, Coombs GH, Engman L, Müller S (2009) Differential inhibition of high and low $\mathrm{Mr}$ thioredoxin reductases of parasites by organotelluriums supports the concept that low $\mathrm{Mr}$ thioredoxin reductases are good drug targets. Parasitology 136: 27-33.

Meotner M, Neta P (1986) Kinetics of electron transfer from nitroaromatic radical anions in aqueos solutions. Effects of temperature and steric configuration. J Phys Chem 90: 4648-4650.

Miškinienė V, Sarlauskas J, Jacquot JP, Čenas N (1998) Nitroreductase reactions of Arabidopsis thaliana thioredoxin reductase. Biochim Biophys Acta 1366: 275-83.
Nivinskas H, Koder RL, Anusevičius Ž, Šarlauskas J, Miller A-F, Čènas N (2001) Quantitative structure-activity relationships in twoelectron reduction of nitroaromatic compounds by Enterobacter cloacae NAD(P)H:nitroreductase. Arch Biochem Biophys 385: 170-178.

Nordberg I, Arner ESJ (2001) Reactive oxygen species, antioxidants, and the mammalian thioredoxin system. Free Radic Biol Med 31: 1287-1312.

Rudolph FB (1979) Product inhibition and abortive complex formation. Methods Ensymol 63A: 411-437.

Rudolph FB, Fromm HJ (1979) Plotting methods for analyzing enzyme rate data. Methods Enzymol 63A: 138-159.

Šarlauskas J, Nemeikaitè-Čènienè A, Anusevičius Ž, Misevičienè L, Martinez-Julvez M, Medina M, Gomez-Moreno C, Čènas N (2004) Flavoenzyme-catalyzed redox cycling of hydroxylamino- and amino metabolites of 2,4,6-trinitrotoluene: implications for their cytotoxicity. Arch Biochem Biophys 425: 184-192.

Šarlauskas J, Nivinskas H, Anusevičius Ž, Misevičienè L, Marozienè A, Čenas N (2006) Estimation of single-electron reduction potentials $\left(E_{7}^{1}\right)$ of nitroaromatic compounds according to the kinetics of their single-electron reduction by flavoenzymes. Chemija 17: 31-37.

Vienožinskis J, Butkus A, Čenas N, Kulys J (1990) The mechanism of the quinone reductase reaction of pig heart lipoamide dehydrogenase. Biochem J 269: 101-105.

Wardman P (1989) Reduction potentials of one-electron couples involving free radicals in aqueous solution. I Phys Chem Ref Data 18: 1637-1755.

Wardman P (1990) Bioreductive activation of quinones: redox properties and thiol reactivity. Free Radic Res Commun 8: 219-229.

Williams CH Jr (1990) Lipoamide dehydrogenase, glutathione reductase, thioredoxin reductase, and mercuric ion reductase: a family of flavoenzyme transhydrogenases, In Chemistry and Biochemistry of Flavoenzymes 3 (Muller F, ed), vol 3, pp 121-211. CRC Press, Boca Raton.

Yang A, Ma K (2009) Characterization of a thioredoxin-thioredoxin reductase system from the hyperthermophilic bacterium Thermotoga maritima. J Bacteriol 192: 1370-1376.

Zanetti G, Williams CH Jr, Masey V (1968) Influence of photoirradiation on the oxidation-reduction state of thioredoxin reductase. J Biol Chem 243: 4013-4019. 